\title{
Mind as a dimension \& compassion as a relationship issue
}

\author{
Martin Seager
}

\begin{abstract}
In the following paper it is argued that within a mistaken materialistic western scientific paradigm, mind is incorrectly reduced to brain. Such bad science means that compassion, along with many other phenomena relating to the domain of mind, tends to be measured in a depersonalised and objectified way. This objectification of compassion renders it almost impossible to design care services that will promote and sustain empathic connections between caregivers and recipients of care. This is simply because of a failure to recognise that compassion is a dynamic and interactional product of relationship within a live human context. A more psychologically-minded framework is proposed that honours mind as a dimension of the universe alongside time and space. Within this framework it becomes much easier to recognise and honour the universal psychological needs of the human condition. Within this approach the language of poetry and art is shown to be more relevant to compassion than the language of traditional western science. It also follows from this that it is of the utmost importance to recognise the powerful relational impact on carers of the caring role. If we want true care to be provided, we must also take care of the minds of those whom we expect to give care and attention to others.
\end{abstract}

Keywords: Compassion, Empathy, Relationship, Mind, Science

\section{Background}

Compassion is very much the "buzzword" of our time with reference to what constitutes good healthcare. It has acquired an almost mythical status and health care professionals are increasingly pilloried for lacking "it" But in many ways this is a tautology. Compassion is a large part of what is meant by "care" in the first place. Asking for compassionate care is therefore like asking for wet water. Honouring and generating compassion has always been vital if we are to improve not just the quality of healthcare but the caring quality of society as a whole. Compassion is an ancient part of the human condition and the core of civilization and all major religious faiths.

However, how do we define and measure compassion? The very concept of compassion taps into a philosophical problem that lies at the very heart of western science. Are human beings nothing more than the sum of their brains, bodies and physical processes or is there something more going on? Can mind and the human heart or spirit (quality, meaning) be reduced to matter

\footnotetext{
Correspondence: mjfjseager@tiscali.co.uk
}

Honorary Consultant Psychologist, Central London Samaritans, Marshall Street, London W1F 9BF, UK (quantity, number) or does mind have its own scientific legitimacy as a part of our universe?

This paper takes the epistemological view that to reduce compassion along with all the subjective, interpersonal and psychological phenomena that we call "mind" to the "objective" brain is bad science and amounts to what Raymond Tallis [1] has called "neuro-mania" and what I would call "mind-blindness" extending Simon Baron-Cohen's [2] term. This paper is based therefore upon the more psychologically minded assumption that there can be no proper scientific study of human beings or indeed the universe as a whole, if mind is devalued by being either split from matter (as a "ghost in the machine"b) and/or reduced to it (as non-existent). No observation can be made outside of the dimensions of time or space, but equally no observation can be made outside of the dimension of mind. Objectivity is not superior to subjectivity and in truth depends upon it. Science can only ever be the collective search for objective patterns and themes in subjective observations. It is ironic therefore that even when we come to study the human mind itself, we try to factor subjectivity out of our calculations. This leaves us only with a mindless pseudo-science. 


\section{Compassion \& pseudo-science}

In a materialistic scientific paradigm ${ }^{c}$ it is assumed that we can somehow only truly measure compassion in a depersonalised and objectified way and this then becomes a neuro-maniacal search for a biological basis for compassion ("mirror neurons"). The essential mindbased and relationship-based nature of compassion thus get watered down at best into a mysterious (soft) moral value within which physical techniques of care are thought to be delivered. In this split world, the "hard" data are equated with true science (the baby) and the soft data are subtly relegated to the background (the bathwater). Science gets split from art and from spiritual concerns. The emotional and mental lives of humans can only be allowed to exist within this pseudo-scientific world under the depersonalised title "affect" and love only exists as an "affiliative bond". We are already lost. Our language has killed the very thing we are searching for.

Clearly, a quantum paradigm cannot be all-encompassing in explaining our universe for the following simple reason: if the universe is entirely reducible to physics and mathematical formulae, and if the mind can be reduced to the brain, why is there any need to ask questions or interpret what is going on in the universe at all? Why also would there be any need at all for anything "soft" like a value? Putting this another way, Newton may have observed gravity in the fall of an apple but the universe also contains Newton himself and his need to question, theorise about, give value to and interpret the universe through his own observing mind. As long ago as 1958 Carl Rogers said "For it is not upon the physical sciences that the future will depend. It is upon us who are trying to understand and deal with ... interactions ... who are trying to create helping relationships" (my italics).

\section{There is only one true way to measure a mind}

Once we accept the scientific legitimacy of mind and relationship as something that is related to but differentiated from matter and an equally important dimension of our universe, it gets a lot easier to measure the mind and a lot easier to measure compassion. It also gets a lot easier to explain why compassion is inevitably so elusive to "objective" measurement when from a "subjective" point of view it is usually quite obvious.

There is in fact only one way to measure a mind and that is with another mind in a live relationship [3]. We use physical metaphors like "tuning in", "resonating", "interpersonal chemistry", "mirroring" and "connecting" to try to describe human relationships precisely because they cannot be literally quantified. They are interactions happening at the level of mind and meaning. Spatial metaphors such as "inner world" or "mind space" are only needed precisely because the domain of mind is truly something different from physical space. This is not that mysterious. Modern technology is indeed already able to show us some important correlations between subjective experiences (mind) and objective brain activity. In any correlation both factors are surely validated as different but related entities. However, within traditional western science, instead of using such correlational evidence to validate the dimension of mind, only the brain activity is legitimised as hard data, as if the brain process is all that is really going on. The truth is, though, that however much we know, for example, that seeing the colour yellow is correlated with the activity of specific retinal and brain cells, the experience of yellowness is a real phenomenon at the mind level and can never be reduced or understood except subjectively. If this is true even for simple colour perception, how much more true must it be for more complex psychological phenomena? Without a mind dimension to the universe, there could be no interpretation of any data and no search for data. Without a mind dimension, there could not be any meaning, theory, belief, ambiguity, language, information, metaphor, communication or science itself.

Mind, compassion, relationship and the human condition The importance of mind (as distinct from brain) is particularly obvious when we recognise that all human beings want to feel understood, loved, heard, valued and part of a social group. These are indeed some of the core and universal psychological needs of the human condition [4]. Any adult human being subjectively knows the difference between being genuinely listened to and being politely ignored. Every child can subjectively feel the difference between being truly loved and not being wanted. These subjective feelings of love and attachment have been shown to impact on the developing brain $[5,6]$ and so are far from being "soft" background factors. Genuineness and sincerity are qualities that can only be registered subjectively in a live relationship. Two people can speak exactly the same words but one may have authenticity and one may not. The subjective component is absolutely vital both for the speaker and the listener. The mind can never be objectively read through the brain or the body. This does not mean that relationships cannot be subjected to any scientific thinking at all, but a different kind of thinking is required - looking at nature from the "inside out" rather than from the "outside in" and using interpersonal rather depersonalised theories. This means looking for rich interactional patterns in subjectivity, not trying to factor it out in the false search for something objective.

Carl Rogers [7,8] long ago identified key elements of effective human caring relationships as being empathy, warmth and genuineness. However, within our materialistic scientific paradigm, these ideas from Rogers (and others) have been wrongly disqualified as not constituting "hard" science and have instead been viewed as at best "soft" values in which some more critical, supposedly active 
technique of care is delivered. Once we remove the materialistic distortion of pseudo-science, however, it becomes obvious that Rogers was directly observing the very factors that do transmit care between people - they are the baby not the bathwater. This means that as scientists of the human condition we should if anything be studying relationship factors and interactional patterns in more detail and depth. The empirical evidence for the validity of these ideas is however already there in abundance if we choose to see it.

Whitehorn and Betz [9] in a study reported by Rogers [8] investigated the therapeutic outcomes of a sample of young resident physicians with "schizophrenic" inpatients. They chose for special study the seven most successful physicians and the seven whose patients had shown the least degree of improvement. What they found when comparing the approaches between these two groups was that the most successful physicians had related to their patients in terms of what personal meanings their symptoms had for them whereas the least successful physicians had been more concerned with achieving symptom reduction in terms of "objective" diagnostic criteria. The successful physicians were therefore "relating to" their patients empathically and compassionately as fellow human beings and it is not surprising therefore that they were also found to be much more likely to have earned their trust and confidence.

The same clear picture applies to talking therapy outcomes. Whenever psychotherapies are measured, "relationship factors" are at the root of all good outcomes regardless of the therapy "brand" [10]. Again, these factors are clearly the baby, not the bathwater. When asked to review for the national Samaritans how talking relationships can help (or harm) people I obtained similar findings to Rogers by investigating not just therapy relationships but also the patterns of helpful communication in everyday life, religion and the arts. I found that all helpful human relationships contained two core elements: attachment and empathy. In my investigation attachment was defined, following Bowl by, primarily in terms of a caregiving relationship in which the caregiver had an emotional investment in the person being cared for. Empathy, on the other hand, was defined as the caregiver's capacity to "tune in with" or connect with the other person accurately by using their own personal experience to identify with their situation. I observed that empathic identification underpins not only all good therapy, health and care work but also all healthy human relationships. Empathic identification through prayer and communion is also what is sought in faithbased relationships to God, however culturally defined.

What all this shows is that our common beliefs about therapies and helping relationships in general are the wrong way round. Empathy is not a "soft" background variable in which techniques of practical care are delivered. In truth, paralleling Chomsky's linguistic theory ${ }^{\mathrm{d}}$, empathy is itself operating at the level of deep structure and can be translated into a variety of different therapeutic languages or actions at the surface level. Empathy reflects an emotional or even spiritual connection between people that is vital for our existence, nurturance and development. Recent research in the field of "mentalization" (e.g. [11]) has also begun to show the important links between attachment, empathy and the development of a healthy human personality. It can only be within a secure attachment that the process of empathic identification and attunement between the caregiver and the baby can unfold in a stable and secure way. Without the mirroring and attunement of empathy, which for the first two years of life is conveyed physically without symbolic language, a baby cannot develop any accurate or healthy sense of self or identity. Words and symbols only come later and have little emotional meaning if they are not congruent with the true emotional state [12].

Indeed, as a story-telling species, human beings from childhood onwards need constantly to be nurtured in their imaginations by a constant diet of stories, representations and identifications relating to their own lives. Humans are in a state of constant connection and identification in their everyday lives which gives a sense of meaning and belonging. This constant emotional nutrition involves being able to identify with others who are like us.

At this point therefore it is important not to get too distracted by the exact demarcations between empathy, sympathy, compassion, warmth, attachment and genuineness. These are all aspects of the broader and more familiar term "love". Love is the most fundamental aspect of the human condition and we can all recognise its presence or absence without needing pseudo-scientific equipment. Nobody in their right mind would choose their partner in life by using a galvanic skin response test or an MRI scan. And yet our society is increasingly falling foul of this kind of pseudo-science as an "evidence-base" to shape and influence major decisions about human relationships, care and wellbeing. Freud [13] originally called psychoanalysis the "love cure". He was not wrong. Human beings need love to develop and relationships can damage us as well as make us whole. However, it is clear that love and care cannot be taught objectively as skills or techniques. They can only be developed in relationship through lived experience. The only way truly to learn empathy is to be at the receiving end of it.

\section{Finding the right language for compassion}

If we are to talk about the psychology of the human condition in a truly accurate way, therefore, we need a personalised language, which allows us to identify, not a depersonalised language. This we already have in abundance, 
for example in poetry, novels, plays, films and also in religious and spiritual texts. By factor-analysing the content of human art and religion we would have no problem in identifying and "objectifying" the patterns and themes that are critical to compassion within the human condition. It is striking that such an analysis has never been attempted because since the $18^{\text {th }}$ Century art and religion have not been seen as a proper source of scientific knowledge, even about our own humanity.

However, once art, culture, everyday life and religion are factored in, one of the most striking things about the human species is the need to make connections and identifications between people. Humans are a storytelling species. There is a constant need to identify with fictional characters in our plays, films, novels, songs, religious services and TV programmes. Most songs are love songs, conveying how it feels to be secure in love or abandoned. The emotion and meaning in art and religion is immediately recognisable in a way that is much more measurable than if it were translated into the language of western science. Here is what a poem about love might look like if it were translated into the language of pseudo-science that still dominates western thinking.

\section{The Empirical Love Song of Alfred E. Prefab}

An affectional bond has been detected

A skin response has been affected

Neurotransmitters are activated

And positive affect correlated

The cortex has been stimulated

And dopamine invigorated

What else is there now to be stated?

"Empirical love" is validated!

The humour in this poem hopefully shows how inadequate traditional scientific language is for describing the psychology of the human condition (including humour itself).

Let us now compare this with an excerpt from a serious and poignant poem by a student nurse called Molly Case presented at the RCN annual conference in 2013 who was passionately defending her beleaguered profession against a tide of bad publicity in relation to compassion.

One lady passing had no relatives to stay,

We sang her to sleep, let angels carry her away.

Were you there that day when we held her hand?

Told her nothing would harm her, that there was a higher plan?

Saw her face as she remembered a face she once held? Saw her breath in the room as she finally exhaled?

Reading this poem creates an automatic connection to the feelings of the author, the sad situation of the dying woman and the immeasurable and even sacred value of nursing at its best. Having read these words, we are touched personally and may even find tears welling up in our own eyes. We are identifying and empathising. This is a genuine response that cannot be faked. We have measured the situation at the level of our own hearts and minds simply through the process of the written word. This shows the value of poetic language for making psychological connections between minds. It is also clear just how inappropriate and redundant it would be to try to measure the compassion in this situation "objectively". Where would we start? Perhaps by strapping a galvanic skin response recorder to the patient or to the nurses? What would the readings show us? We would still have to interpret the readings. Such clumsy attempts at measurement would of course undermine the relationships and detract from their humanity, spontaneity and authenticity. In essence, this kind of pseudo-scientific monitoring would kill the very thing it was trying to measure.

\section{Keeping compassion alive in care systems - from an Individualistic to a relational concept Compassion as not primarily a skills or training issue}

In a previous publication [14] I argued that it cannot be helpful to objectify compassion as a capacity or skill that can be taught through educational programmes. People do indeed differ in their individual capacity for compassion but those who choose caring roles (paid or unpaid) are by definition more likely on average to possess these qualities than those who do not. Learning compassion is something that healthy human beings do as part of their own natural personality development within family relationships from the earliest attachment onwards. However, although training cannot instil these qualities from scratch if they are not already present it can help us make better use of existing empathy and compassion. If training itself conveys real empathy for the situation of those being taught it is "congruent" and has more chance of promoting some emotional nurturance and development of care staff as part of a supportive culture. Training like any human activity is ultimately based on relationships which can be effective, ineffective or even detrimental. Carl Jung ${ }^{\mathrm{e}}$ stated:

\section{One looks back with appreciation to the brilliant teachers, but with gratitude to those who touched our human feelings. The curriculum is so much necessary raw material, but warmth is the vital element for the growing plant and for the soul of the child.}

From this it is clear that training is not just about content but also about the quality of relationships in which it is provided and which it embodies. The same training, if delivered cynically to "tick a box", will not work compared to a situation where it is delivered with compassion for 
those receiving it. Training has to practice what it preaches or as Gandhi famously put it "we must be the change that we wish to see in the world" (my italics).

\section{From teaching compassion to sustaining carers and preventing compassion breakdown}

Whilst teaching and training can have value under the right conditions, a more valid objective is to nurture, sustain and protect the empathy and compassion that is already there in people. Seager [14] set out an interactional $(A B C)$ model of compassion in which it is shown that compassion from person A to person B cannot survive in a relational vacuum or in a toxic environment but requires external supportive and nurturing relationships $(C)$. Under this model the amount of energy available for compassion at any point in time in a relationship depends not just upon internal capacities of the caregiver but is also directly influenced by external burden and support factors. No human being can give unlimited compassion and all human beings will shut down or burn out emotionally if overloaded, however compassionate, resilient and highly trained they might be. For example, no GP can properly attend to patient number 15 in the day if they haven't had a chance to emotionally process numbers $1-14$. This is not primarily a skills issue, but the GP would need to be aware of this emotional need and also have the support to meet that need on a daily basis. Seager identified how empathy and compassion between people can be violated or ruptured not just in obvious active ways (for example by negative remarks) but also in a passive and less intentional ways:

\section{When words convey a failure of empathy, in other} words showing that the listener's state of mind is too disinterested, distracted, unreceptive, insensitive or "out of tune" with that of the speaker (passive harm).

Compassion in our public services is not therefore so much an issue of technique or of training as of culture. Certain environmental conditions can foster compassion and a "culture of listening" and other conditions can undermine it. $[15,16]$ refers to the notion of the "professional family" which like ordinary families can be healthy or unhealthy. Ballat \& Campling [17] insightfully illustrate how modern market-driven public healthcare cultures can become toxic and they appeal to the concept of "intelligent kindness" and an ancient and universal notion of "kinship" within human communities as a framework for optimising both human and financial value within care organisations and settings.

\section{Discussion}

Once we adopt a psychologically-minded (not mindless) paradigm, compassion is fairly easy to detect. It exists in all our lives and examples of failures and successes of compassion abound. The world of art, literature and story-telling is full of it. No-one owns compassion and it does not need to become branded as yet another set of techniques or pseudo-skills in our industrialised health care system. It is ancient and universal. Compassion is part of all successful care, whether delivered by a doctor, nurse, therapist, priest, friend, teacher or even a bank manager. There is also no lack of empirical evidence. Carl Rogers, amongst other psychological scientists, set out many of the core elements of compassion many years ago and showed how they relate to effective care. Over the centuries before Rogers, many spiritual leaders, philosophers and thinkers have also thought and written on the subject. For example, Charles Darwin saw sympathy as a fundamental instinct of our human species ${ }^{\mathrm{f}}$. The universal themes and patterns behind human compassion are clear and consistent across time and culture. There is no need for more and more pseudo-scientific analysis of compassion at a biological level. It would be more helpful to factor-analyse the psychosocial contents of our art and literature. All human beings from their earliest childhood can recognise when love is there and when it is not. Recognising and responding to compassion or the lack of it is part of the survival repertoire of all human beings.

The hardest task is therefore not that of recognising compassion or even delivering it at a personal level. Far more complicated is the task of keeping compassion alive in those settings like hospitals and care homes where caregivers are under great pressure to keep caring and where resources are limited. In this respect, the breakthrough needed is to accept that providers of care do not work in a psychological vacuum but as human beings themselves need to be supported by relationships that meet the same standards of empathy, enabling the impact of their caring to be processed and the energy required for caring to be constantly renewed. Ultimately, care can only successfully be provided by a carer who is also cared for.

\section{Endnotes}

a Particularly since the publication of Francis, R., QC (2013) Mid Staffordshire NHS Foundation Trust Public Inquiry Final Report.

${ }^{\mathrm{b}} \mathrm{A}$ phrase coined by Gilbert Ryle with "deliberate abusiveness" in his book "The Concept of Mind" (1949) which attempted (unsuccessfully) to demonstrate that the whole Cartesian concept of mind as distinct from matter is the result of a "category error".

"Ironically originating from the "age of reason and enlightenment" and the death of "natural philosophy" from the late 17th Century onwards.

dStarting with his book "Syntactic Structures" (1957).

"From his book "The Development of Personality" (1953). 
fIn "The Descent of Man, and Selection in Relation to Sex" (1871).

\section{Competing interests}

The author declares that he has no competing interests.

\section{Acknowledgement}

I would very much like to thank Sue Shea for inviting me to write this paper and for her ongoing support and collaboration within the field of

compassion

Received: 5 June 2014 Accepted: 17 July 2014

Published online: 11 November 2014

\section{References}

1. Tallis R: Aping Mankind: Neuromania, Darwinitis and the Misrepresentation of Humanity. Acumen Publishing; 2011.

2. Baron-Cohen S: Mindblindness: An Essay on Autism and Theory of Mind. Bradford Books, the MIT Press; 1995.

3. Seager M: Bad Science and Good Mental Health, Therapy Today, September, Vol. 23, Issue 7. British Association of Counselling and Psychotherapy (BACP) 2012.

4. Seager M, Orbach S, Sinason V, Samuels A, Johnstone L, Fredman G, Antrican J, Hughes R: National advisory group on mental health, safety and well-being - towards proactive policy: five psychological principles. 2007. [https://www.southstaffsandshropshealthcareft.nhs.uk/Services/ Psychological-Services/Psychological-Services-Strategy/General-Information/ docs/5-universal-psychological-principles.aspx].

5. Gerhardt S: Why Love Matters: how affection shapes a baby's brain. Hove: Routledge; 2004.

6. Schore A: The effects of secure attachment relationship on right brain development, affect regulation and infant mental health. Infant Mental Health Journal 2001, 22:7-66.

7. Rogers C: The Necessary and Sufficient Conditions of Therapeutic Personality Change. Journal of Counselling Psychology 1957, 21:95-103.

8. Rogers CR: The characteristics of a helping relationship, Personnel \& Guidance Journal, September Issue. 1958.

9. Whitehorn JC, Betz BJ: A study of Psychotherapeutic relationships between Physicians and Schizophrenic patients. Am J Psychiatry 1954, 111:321-331.

10. Norcross JC (Ed): Psychotherapy Relationships That Work New York. NY: Oxford University Press; 2002

11. Fonagy $\mathrm{P}$, Gergely $\mathrm{G}$, Jurist EL, Target M: Affect regulation, Mentalization and the Development of the Self. New York: Other Press; 2002.

12. Seager M: Attachment theory as a basis for informing service systems, cultures and environments. In Attachment Theory in Adult Mental Health: A Guide to Clinical Practice. Edited by Danquah A, Berry K. Routledge; 2013.

13. Freud S: Letter to Jung as quoted in Freud and Man's Soul (Bettelheim, B., 1983). Knopf; 1906. ISBN 0-394-52481-0.

14. Seager M: Who cares for the carers? Keeping compassion Alive in Care Systems, Cultures and Environments: A Psychologically-Minded Approach, Chapter in 'Providing Compassionate Health Care: Challenges in Policy and Practice.' Routledge; 2014. in press.

15. Psychological Safety: A Psychoanalytically Informed Contribution towards "Safe, Sound and Supportive" Mental Health Services. Psychoanalytic Psychotherapy 2006, 20(4):266-280.

16. Seager M: Psychological safety: A missing Concept in Suicide Risk Prevention. Chapter 17 in "Relating to Suicide \& Self-Harm". Routledge; 2008.

17. Ballat J, Campling P: Intelligent Kindness. RC Psych Publications; 2011.

doi:10.1186/s40639-014-0003-y

Cite this article as: Seager: Mind as a dimension \& compassion as a relationship issue. Journal of Compassionate Health Care 2014 1:3.

\section{Submit your next manuscript to BioMed Central and take full advantage of:}

- Convenient online submission

- Thorough peer review

- No space constraints or color figure charges

- Immediate publication on acceptance

- Inclusion in PubMed, CAS, Scopus and Google Scholar

- Research which is freely available for redistribution

Submit your manuscript at www.biomedcentral.com/submit 